\title{
How time-inconsistent preferences influence venture capital exit decisions? A new perspective for grandstanding
}

\author{
Yanzhao Li ${ }^{1}$, Ju-e Guo', Shaolong Sun ${ }^{1} \mathbb{B}$ and Yongwu Li $i^{*^{*}}$
}

\author{
${ }^{*}$ Correspondence: \\ liyw@bjut.edu.cn \\ ${ }^{2}$ College of Economics \\ and Management, Beijing \\ University of Technology, No. \\ 100 , Ping Le Yuan, Chaoyang \\ District, Beijing 100124, China \\ Full list of author information \\ is available at the end of the \\ article
}

\begin{abstract}
Considering that the assumption of time consistency does not adequately reveal the mechanisms of exit decisions of venture capital (VC), this study proposes two kinds of time-inconsistent preferences (i.e., time-flow inconsistency and time-point inconsistency) to advance research in this field. Time-flow inconsistency is in line with the previous time inconsistency literature, while time-point inconsistency is rooted in the VC fund's finite lifespan. Based on the assumption about the strategies guiding future behaviors, we consider four types of venture capitalists: time-consistent, time-pointinconsistent, naïve, and sophisticated venture capitalists, of which the latter three are time-inconsistent. We derive and compare the exit thresholds of these four types of venture capitalists. The main results include: (1) time-inconsistent preferences accelerate the exits of venture capitalists; (2) the closer the VC funds expiry dates are, the more likely time-inconsistent venture capitalists are to accelerate their exits; and (3) future selves caused by time-flow inconsistency weaken the effect of time-point inconsistency. Our study provides a behavioral explanation for the empirical fact of young VCs' grandstanding.
\end{abstract}

Keywords: Venture capital, Time-inconsistent preferences, Start-ups, Exit decisions, Real options

JEL Classification: G24, D81, G31

\section{Introduction}

Venture capital (VC) provides the imperative capital for the development of start-ups (Cumming 2012; Tavares-Gärtner et al. 2018; Ferreira and Pereira 2021). Additionally, due to its unique mode of operation, VC plays a role in coping with risks, facilitating venture success, and nurturing high-tech industries worldwide, especially in transition economies such as China (Guo and Jiang 2013). According to KPMG's quarterly report on VC trends named "Venture Pulse", both Asian and global VC transactions increased by more than $40 \%$ in 2018 , reaching a record of $\$ 93.5$ billion and $\$ 254.7$ billion US dollars, respectively. Among them, Chinese VC transaction volume reached a record of 70.5 billion US dollars, with an increase of 52.9\%, compared with 46.1 billion US dollars in 2017 (KPMG 2019).

(c) The Author(s), 2022. Open Access This article is licensed under a Creative Commons Attribution 4.0 International License, which permits use, sharing, adaptation, distribution and reproduction in any medium or format, as long as you give appropriate credit to the original author(s) and the source, provide a link to the Creative Commons licence, and indicate if changes were made. The images or other third party material in this article are included in the article's Creative Commons licence, unless indicated otherwise in a credit line to the material. If material is not included in the article's Creative Commons licence and your intended use is not permitted by statutory regulation or exceeds the permitted use, you will need to obtain permission directly from the copyright holder. To view a copy of this licence, visit http:// creativecommons.org/licenses/by/4.0/. 
The exit, divestment from the VC's portfolio, is crucial since it achieves the sale of shares and thus determines the VC fund's final payoffs. Consequently, exit payoffs are an important signal of VC funds' quality (Cumming 2010). Particularly, for young and lessprestigious VC funds, exit payoffs may be the only quality signal and directly affect subsequent fundraising (Cumming 2010; Gompers 1996). Therefore, young VCs are more likely to grandstand by pushing firms to go public or sell privately held firms earlier than older VCs (Gompers 1996; Lee and Wahal 2004; Amor and Kooli 2020). Considering that young VCs are more prone to time-inconsistent behavior than older $\mathrm{VCs},{ }^{1}$ this study, for the first time, aims to provide a behavioral explanation for young $\mathrm{VC}$ grandstanding from the perspective of decision-makers' time preferences. Specifically, we explore the optimal exit decisions of venture capitalists under time-inconsistent preferences.

Previous studies have investigated various factors influencing VC exit decisions, such as legal institutions and agency problems. For example, Cumming et al. (2006) provide the first cross-country empirical insight into the relationship between legality and VC exits based on a sample of 12 Asia-Pacific countries and regions. Cumming (2008) documents that strong VC control increases the likelihood that start-ups would exit through trade sales rather than through initial public offerings (IPOs). Anderson et al. (2017) report the effects of political ties of $\mathrm{VC}$ funds on $\mathrm{VC}$ exits and find that political ties facilitate VCs' successful exits via Chinese stock and mergers and acquisitions (M\&A) markets. However, these studies rely on the assumption that individuals are perfectly rational. Recently, pioneering research in behavioral finance has discovered many decision biases, thus effectively explaining the anomaly and puzzle phenomenon in reality (Tian 2016). Nevertheless, only a few studies have attempted to incorporate behavioral finance theory into the VC exit decision research. Notably, Bock and Schmidt (2015) first examine the determinants of VC exit behavior after the lockup expiry in IPOs by considering insights from prospect theory. Nevertheless, the intertemporal choice of $\mathrm{VC}$ exit decisions and the resulting time-inconsistent preferences have been neglected in previous studies. $^{2}$

Many experimental studies on time preferences suggest that time-inconsistent preferences are more realistic than time-consistent preference, and they seriously distort the behavior of decision-makers (Strotz 1955; Thaler 1981; Loewenstein and Prelec 1992). Concretely, time-inconsistent preferences assume that decision-makers' discount rates for payoffs decrease over time. Therefore, decision-makers prefer current payoffs rather than future payoffs (Laibson 1997; O'Donoghue and Rabin 1999; Grenadier and Wang 2007). By relaxing the assumption of constant discount rates, time-inconsistent preferences provide a new theoretical perspective for accurately describing decision-makers' behavioral choices. As a result, time-inconsistent preferences are widely used in many fields such as investment (Grenadier and Wang 2007; Tian 2016; Luo et al. 2020),

\footnotetext{
${ }^{1}$ Young VCs rely more on individual decisions, whereas older VCs have well-established decision rules and processes Grenadier and Wang (2007) argue that individuals or small private partnerships are more prone to time inconsistency than firms, because the organizational structure and professional management of firms may mitigate or remove the time inconsistency from the firms' decisions.

${ }^{2}$ Yoon (2020) praises time inconsistency in intertemporal choice as one of the most influential findings in the judgment and decision literature.
} 


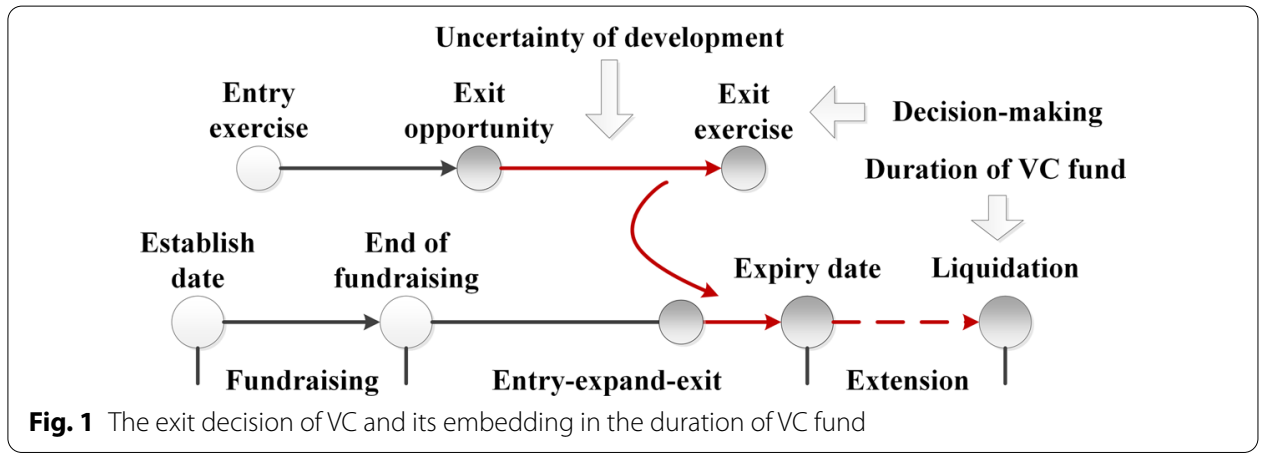

consumption (Liu et al. 2020), insurance (Chen et al. 2016) and contract design (Li et al. 2016; Wang et al. 2020).

Time-inconsistent preferences mentioned earlier are caused by individual time preferences, which essentially depend only on the individual's time sensitivity to flow payoffs. Beyond that, the finite lifespan of VC funds, determined by VC's particular organizational structure, ${ }^{3}$ is also a source of time inconsistency among venture capitalists. The finite lifespan of VC funds forces venture capitalists to sell all projects before maturity. Although VC funds always have extension periods to facilitate exits, fund investors (limited partners) observe the delayed exit behavior of venture capitalists and then evaluate the quality of VC funds accordingly (Gompers 1996; Cumming 2010; Amor and Kooli 2020). This pressure makes venture capitalists have a lower utility perception of payoffs after the expiry date. We can find relevant evidences from previous research on the finite lifespan of VC funds. For example, Kandel et al. (2011) prove that the termination of all unfinished projects at the fund's maturity leads to suboptimal decisions during later stages of investment. And they sum up this phenomenon as venture capitalists' myopia induced by the finite lifespan of VC funds. Additionally, Arcot et al. (2015) investigate whether secondary buyouts are value-maximizing, or reflect opportunistic behavior and demonstrate that $\mathrm{VC}$ funds under expiration pressure engage more in secondary buyouts. Therefore, it is reasonable to believe that the discount rate of venture capitalists drops rapidly after VC funds expiring, also in line with time-inconsistent preferences. Consistent with this, Guo et al. (2018) present a similar argument. For the long-term transit investment problem, the utility of transit projects completed during and outside the term is significantly different for city mayors.

To distinguish the two kinds of time inconsistencies mentioned, we propose timeflow and time-point inconsistencies to promote understanding of $\mathrm{VC}$ exit decisions. As shown in Fig. 1, the exit decision of VC starts with an exit opportunity and ends with the exit exercise. Thus, if venture capitalists exercise the exit option before the expiration, the perceived exit payoffs are affected by time-flow inconsistency. Additionally, if venture capitalists exit during the extension period, both time-flow and time-point inconsistencies influence the perceived exit payoffs. Based on the assumption about the strategies guiding the future behaviors (Grenadier and Wang 2007; Tian 2016), we consider four

\footnotetext{
${ }^{3}$ The limited partnership has been the main organizational form of VC funds for the past three decades. It is designed with a finite lifespan: about 8-10 years, with an extension of 2-3 years allowed to facilitate exit (Gompers and Lerner, 1999; Kandel et al., 2011).
} 
types of venture capitalists: time-consistent, time-point-inconsistent, naïve, and sophisticated venture capitalists, of which the latter three are time-inconsistent. All timeinconsistent venture capitalists are aware of time-point inconsistency, but naive venture capitalists misunderstand time-flow inconsistency and assume that the future selves caused by time-flow inconsistency act according to preferences of the current self. In contrast, sophisticated venture capitalists know that future selves choose strategies that are optimal for themselves.

This study first presents the model setup of venture capitalists' time-inconsistent preferences and develops an optimal VC exit decision ${ }^{4}$ through trade sales ${ }^{5}$ based on the fact that the $\mathrm{VC}$ and the acquiring firm share synergies brought by the M\&A. Then, we derive the optimal exit thresholds of the four types of venture capitalists using the wellestablished real options approach, ${ }^{6}$ considering the uncertainty and option nature of VC exits. Finally, a comparative static analysis and the corresponding model implications are presented. The main results are summarized as follows: (1) time-inconsistent preferences accelerate the exit of venture capitalists, verifying the grandstanding of young VCs; (2) the closer the VC funds expiry dates are, the more likely time-inconsistent venture capitalists are to accelerate their exits; and (3) future selves caused by time-flow inconsistency weaken the effect of time-point inconsistency. Under the action of these mechanisms, we can observe that (1) all time-inconsistent venture capitalists exit earlier than the time-consistent ones; (2) generally, sophisticated venture capitalists exit earlier than naïve venture capitalists, who in turn exit earlier than time-point-inconsistent venture capitalists; and (3) when the degree of time-point inconsistency is much greater than that of time-flow inconsistency, and the exit opportunity is close to the VC fund's expiry date, naive venture capitalists exit later than time-point-inconsistent venture capitalists, and sophisticated venture capitalists exit last among the three defined time-inconsistent venture capitalists.

Our study contributes to the literature in the following ways. First, to the best of our knowledge, this is the first study to consider VC exit decisions under time-inconsistent preferences. Given the vital role that intertemporal choice plays in VC decision-making, our study broadens the theoretical understanding of VC exit decisions. Second, since Gompers (1996) proposed the grandstanding hypothesis of young VCs, researchers have constantly tried various theories and perspectives such as signal games (Grenadier and Malenko 2011), demand side (Butler and Goktan 2013), and multiple agents (Sethuram et al. 2021), to explain this hypothesis. In contrast to prior studies, we are the first to provide a behavioral explanation from the perspective of time preferences. Third, we extend the decision-making framework of time-inconsistent agents established by Grenadier and Wang (2007). Specifically, we propose time-flow and time-point inconsistencies to model individuals' time preferences and the effect of the finite lifespan of VC funds, respectively. This modeling framework is more realistic for VC exit decisions (Kandel

\footnotetext{
${ }^{4}$ We note that Ferreira and Pereira (2021) also define a similar model. Their model follows the exit dynamic process that is generally consistent with ours, except that they set the premium unilaterally requested by $\mathrm{VC}$, while we determine it by sharing the synergies brought by M\&A.

5 Trade sales (or M\&As) have been the most common exit route for venture capitalists (Bienz and Walz, 2010; Félix et al., 2014; Ferreira and Pereira, 2021).

${ }^{6}$ For the foundation of real options approach, see Dixit and Pindyck (1994). For recent applications of real options in venture capital decision making, see Tavares-Gärtner et al. (2018), and Ferreira and Pereira (2021).
} 


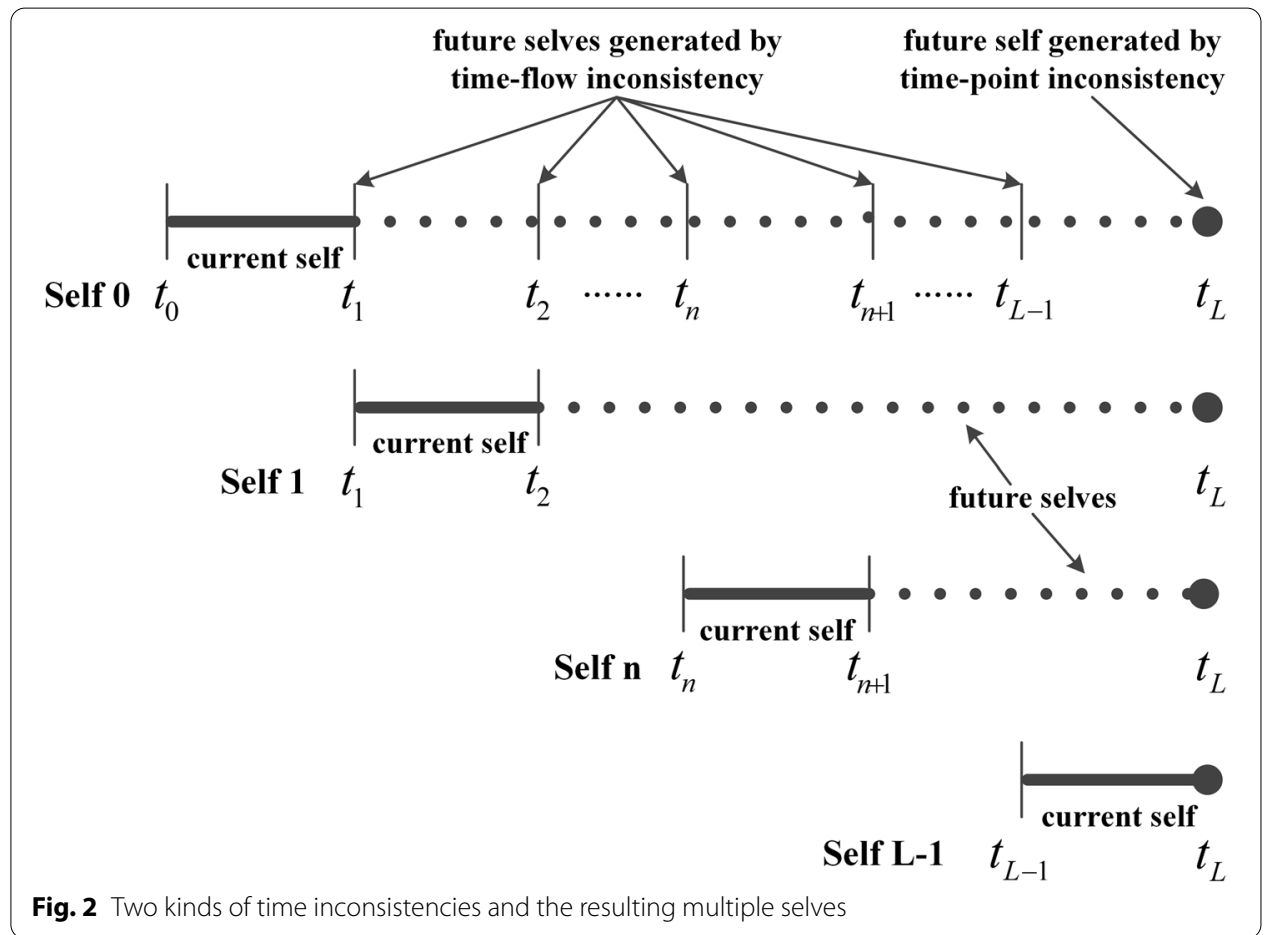

et al. 2011; Ferreira and Pereira 2021) and applicable to other intertemporal choice issues with time restrictions.

The remainder of this paper is organized as follows. "Section Model setup" provides the model setup, including the venture capitalist's time-inconsistent preferences and the exit decision via trade sales. "Section Time-consistent and time-inconsistent venture capitalists" derives the optimal exit timing for time-consistent and time-inconsistent venture capitalists. "Section Model implications" presents the comparative static analysis and model implications. Finally, "Section Conclusions" concludes the paper.

\section{Model setup}

Venture capitalists' time-inconsistent preferences

Following Chen et al. (2016), Harris and Laibson (2013), and Grenadier and Wang (2007), we describe the time-inconsistent preferences of venture capitalists using a continuous-time quasi-hyperbolic discount function. The venture capitalist is described as a finite number of selves with a random lifespan. Each self represents the current stage of the venture capitalist to exercise decision while considering the utility of the future selves exercise decision. As shown in Fig. 2, we call $t_{0}$ the start time moment, which signals the birth of self 0 and means that an exit option emerges for the venture capitalist to sell the share of the invested start-ups. Let $T_{L}$ denote the duration from $t_{0}$ to the VC fund's expiry date. We assume that $T_{L}$ is exponentially distributed with parameter $\lambda_{L}$. Let $t_{n}$ be the birth time of self $n$ and death time of self $n-1(n=1,2,3, \ldots, L-1, L)$. The lifespan $T_{n}=t_{n+1}-t_{n}$ (excluding $T_{L}$ ) for the self $n$ is assumed to be exponentially distributed with the parameter $\lambda_{f}$. If instead the VC fund's expiry date arrives before the next self generated by time-flow inconsistency, the next self is changed to self $L$ 
generated by time-point inconsistency. The duration of the self $L-1$ is assumed to be exponentially distributed with parameter $\lambda_{p}$. We note that $1 / \lambda$ represents the interarrival time of selves because $\lambda$ is the arrival intensity of the Poisson process, thus we have $E\left[(L-1) / \lambda_{f}+1 / \lambda_{p}\right]=E\left[1 / \lambda_{L}\right]$.

We use $D_{n}(t, s)$ to denote the inter-temporal discount function of self $n$, giving self $n$ 's discounted value at time $t$ of one dollar received at the future time $s$. For payoffs obtained in the duration of self $n$, self $n$ uses a standard discount function $e^{-\rho(s-t)}$, where the constant discount rate $\rho>0$. For payoffs obtained after the death of the current self, self $n$ uses the discount function $\delta e^{-\rho(s-t)}$, multiplying a reduction factor $\delta$ based on the standard discount function. After the arrival of self $n+1$, the venture capitalist uses the updated discount function $D_{n+1}(t, s)$ for evaluation. To distinguish the impact of timeflow and time-point inconsistencies, we define the different reduction factor $\delta_{f}$ for self $n$ $(n=0 \sim L-2)$ and $\delta_{p}$ for self $L-1$, where $\delta_{f}>\delta_{p}$ for time-point inconsistency reducing the discounting of payoffs more.

Then the inter-temporal discount function is given by

$$
D_{n}= \begin{cases}e^{-\rho(s-t)}, & \text { if } s \in\left[t_{n}, t_{n+1}\right), \\ \delta e^{-\rho(s-t)}, & \text { if } s \in\left[t_{n+1}, \infty\right),\end{cases}
$$

$$
\text { for } s>t \text { and } t \in\left[t_{n}, t_{n+1}\right) \text {. }
$$

\section{The exit decision via trade sale}

Consider that the venture capitalist has an opportunity to exit the invested start-up by trade sales and the invested start-up has uncertain prospects for development. Let $P_{t}^{T}$ denote the start-up profit at time $t$. We suppose that the profit is given by a geometric Brownian motion:

$$
d P_{t}^{T}=\alpha P_{t}^{T} d t+\sigma P_{t}^{T} d B_{t}, t \geq 0
$$

where $d B_{t}$ is the increment of a standard Wiener process, $\alpha$ is the expected growth rate of the profit, and $\sigma$ is the profit volatility.

Following Thijssen (2008), we assume that the profit $P_{t}^{T}$ consists of a deterministic part, denoted by $Q^{T}$, and a stochastic component, denoted by $X_{t}$. The stochastic shock is assumed to be multiplicative, that is, $P_{t}^{T}=Q^{T} X_{t}$. Similarly, for the acquiring and merged firms, there are $P_{t}^{A}=Q^{A} X_{t}$ and $P_{t}^{M}=Q^{M} X_{t}$. The deterministic component is regarded as a result of competition in the product market. The stochastic component indicates uncertainty. Therefore, the stochastic component follows a geometric Brownian motion:

$$
d X_{t}=\alpha X_{t} d t+\sigma X_{t} d B_{t}, t \geq 0, X_{0}=x .
$$

The discount rate of the acquiring firm is assumed to be the risk-free rate in this M\&A. In addition, the payment of dividends, provided by the invested firm, is far less than the payoff from selling the shares held in the invested firm for the VC. Therefore, the exit can be regarded as the only way to obtain lump-sum payoffs. Thus, even though the profit of the invested firm is given in flows over time, the venture capitalist's time preference does not affect the expected present value of the profit flow generated by the invested firm. 
Gao et al. (2013) highlight that the acquiring firm could expand its business more efficiently by achieving economies of scale and scope. In this study, this positive effect is characterized as a synergy, that is, the deterministic profit generated by the M\&A is larger than the sum of the deterministic profits of the constituent firms, which is $Q^{M}>Q^{A}+Q^{T}$.

The value of the acquiring firm before the M\&A is as follows:

$$
V^{A}(x)=E \int_{0}^{\infty} e^{-\rho t}\left(Q^{A} X_{t}\right) d t=\frac{Q^{A} x}{\rho-\alpha} .
$$

The value of the merged firm after the M\&A is as follows:

$$
V^{M}(x)=E \int_{0}^{\infty} e^{-\rho t}\left(Q^{M} X_{t}\right) d t=\frac{Q^{M} x}{\rho-\alpha}>\frac{Q^{A} x}{\rho-\alpha}=V^{A}(x) .
$$

The value of the start-up's shares held by the VC before the M\&A is as follows:

$$
V_{V C}^{T}(x)=E \int_{0}^{\infty} e^{-\rho t}\left(\phi Q^{T} X_{t}\right) d t=\phi \frac{Q^{T} x}{\rho-\alpha},
$$

where $\phi$ is the VC's share in the start-up.

We assume that the $\mathrm{VC}$ uses the participating convertible preferred (PCP) stock to invest, ${ }^{7}$ which brings the highest payoffs to the VC in the M\&A (Arcot 2014). The exit payoff obtained by the $\mathrm{VC}$ is $P_{V C}(x)$ as follows:

$$
P_{V C}(x)=d+\phi[P(x)-d]
$$

where $P(x)$ is the value of cash or cash equivalents paid by the acquiring company to purchase the entire equity of the start-up and $d$ is the preferential fixed claim in the M\&A. Nonparticipating convertible preferred stock or common stock is equivalent to the exception when $d=0$ and is therefore covered.

The $\mathrm{VC}$ and the acquiring firm negotiate the merger price to obtain a Pareto effective synergistic value distribution. The merger price is determined using the Nash bargaining game equilibrium. We suppose that the negotiation ability of the venture capitalist is $\beta_{V C}$, and that of the acquiring firm is $\beta_{A}=1-\beta_{V C}$. Following Alvarez and Stenbacka (2006), the merger price is the solution to the optimization problem below:

$$
\sup _{p^{*}}\left[P_{V C}(x)-V_{V C}^{T}(x)\right]^{\beta_{V C}}\left[V^{M}(x)-P(x)-V^{A}(x)\right]^{\beta_{A}},
$$

where $P_{V C}(x)-V_{V C}^{T}(x)$ and $V^{M}(x)-P(x)-V^{A}(x)$ are the value-added payoffs obtained by the $\mathrm{VC}$ and the acquiring firm through the M\&A, respectively. Therefore, we find that the Nash bargaining solution is given by

$$
P^{*}(x)=\frac{Q^{T} x}{\rho-\alpha}-\left(1-\beta_{V C}\right) \frac{1-\phi}{\phi} d+\beta_{V C}\left[\frac{\left(Q^{M}-Q^{A}-Q^{T}\right) x}{\rho-\alpha}\right] .
$$

\footnotetext{
${ }^{7}$ Kaplan and Strömberg (2003) report that nearly $80 \%$ of all venture contracts use convertible preferred stock and that in nearly half of those cases the stock is participating.
} 
The exit payoff obtained by the VC is as follows:

$$
\begin{aligned}
P_{V C}^{*}(x) & =\frac{\phi Q^{T} x}{\rho-\alpha}+\beta_{V C}(1-\phi) d+\phi \beta_{V C}\left[\frac{\left(Q^{M}-Q^{A}-Q^{T}\right) x}{\rho-\alpha}\right] \\
& =V_{V C}^{T}(x)+\beta_{V C}(1-\phi) d+\phi \beta_{V C} \Delta V(x) .
\end{aligned}
$$

The above formula shows that the VC payoffs in trade sales consist of three parts. The first part $V_{V C}^{T}(x)$ is the value of the shares held by the $\mathrm{VC}$ when the invested start-up maintains an independent operation, and the second part $\beta_{V C}(1-\phi) d$ is the profit from the priority settlement in the M\&A. The last part $\phi \beta_{V C} \Delta V(x)$ is the synergistic benefits shared by the VC.

The payoff distribution of the $\mathrm{VC}$ by trade sales is a stochastic process affected by market uncertainty. Therefore, it is necessary to choose the optimal exit threshold to maximize the VC payoffs (Li et al. 2017). We set $C$ as the cost of exit for the VC. We expect to maximize the expected value of the $\mathrm{VC}$ exit payoffs:

$$
\sup _{\tau \geq t} E_{t}\left[D_{n}(t, \tau)\left(P_{V C}^{*}\left(X_{\tau}\right)-C\right)\right]
$$

where $E_{t}[\cdot]$ denotes the expectation operator.

\section{Time-consistent and time-inconsistent venture capitalists}

This section discusses the exit decisions of time-consistent and the three types of timeinconsistent venture capitalists. The time-consistent case is the benchmark model. The three defined time-inconsistent cases allow us to explore the net effect of time-point inconsistency and the complex superposition effect of two kinds of time-inconsistent preferences. This modeling setup can provide a systematic insight into the comprehensive impact of time-inconsistent preferences on VC exit decisions.

According to the model setup of venture capitalists' time-inconsistent preferences in "Section Venture capitalists' time-inconsistent preferences", we present the three defined time-inconsistent venture capitalists' decision selves and the interarrival time in Fig. 3. Obviously, $\lambda_{L}<\lambda_{p N}<\lambda_{p s}$. To compare the exit thresholds of self 0 from $t_{0}$, we follow the standard backward derivation procedure, starting with the self $L$ and then moving back to the self 0 . To ensure the same duration left before the expiry date, we have $E\left[1 / \lambda_{L}\right]=E\left[1 / \lambda_{f}+1 / \lambda_{p N}\right]=E\left[(L-1) / \lambda_{f}+1 / \lambda_{p S}\right]$

\section{Time-consistent venture capitalists}

Let $F(x)$ denote the time-consistent venture capitalist's exit opportunity value function and $x^{*}$ be the optimal exit threshold. Then, according to the continuous-time Bellman equation $\rho F d t=E(d F), F(x)$ satisfies the ordinary differential equation below (see Dixit and Pindyck (1994) for details):

$$
\frac{1}{2} \sigma^{2} x^{2} F^{\prime \prime}(x)+\alpha x F^{\prime}(x)-\rho F(x)=0 .
$$

Equation (12) is solved using the following value-matching and smooth-pasting conditions: 


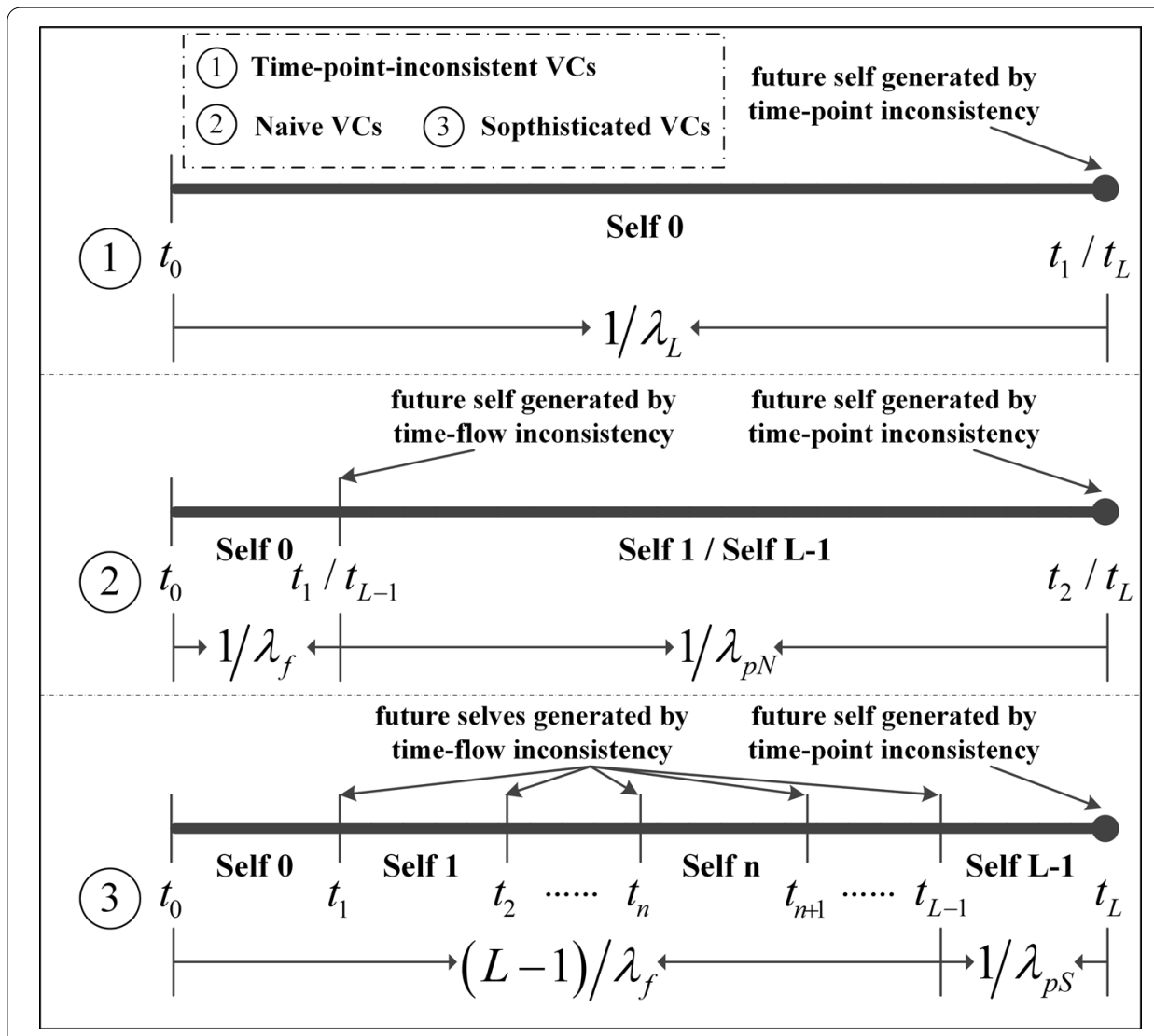

Fig. 3 The exit decision comparison of the three defined time-inconsistent venture capitalists

$$
F\left(x^{*}\right)=P_{V C}^{*}\left(x^{*}\right)-C, \quad F^{\prime}\left(x^{*}\right)=\left[P_{V C}^{*}\left(x^{*}\right)-C\right]^{\prime}
$$

The implied condition of the stochastic process is $F(0)=0$, and we note that the general solution $F(x)=A x^{\beta_{1}}$, where $\beta_{1}=\frac{1}{2}-\frac{\alpha}{\sigma^{2}}+\sqrt{\left(\frac{\alpha}{\sigma^{2}}-\frac{1}{2}\right)^{2}+\frac{2 \rho}{\sigma^{2}}}>1$.

The exit threshold $x^{*}$ is given by

$$
x^{*}=\frac{\beta_{1} \theta}{\left(\beta_{1}-1\right) \eta},
$$

where $\eta=\frac{\phi\left[Q^{T}+\beta_{V C}\left(Q^{M}-Q^{A}-Q^{T}\right)\right]}{\rho-\alpha}$ and $\theta=C-\beta_{V C} d(1-\phi)$.

Equation (13) reveals that when the exit cost $C$ increases, $x^{*}$ increases $\left(\frac{\partial x^{*}}{\partial C}>0\right)$. In turn, when the venture capitalist's negotiation ability $\beta_{V C}$ increases or the fixed income $d$ increases, $x^{*}$ decreases $\left(\frac{\partial x^{*}}{\partial \beta_{V C}}<0\right.$ and $\left.\frac{\partial x^{*}}{\partial d}<0\right)$.

The option value $F(x)$ before exiting is given by

$$
F(x)=\left(\frac{x}{x^{*}}\right)^{\beta_{1}}\left(\eta x^{*}-\theta\right)
$$




\section{Time-point-inconsistent venture capitalists}

The assumption about the time-point-inconsistent venture capitalist is natural for the following reasons. First, venture capitalists cannot ignore the impact of time-point inconsistency due to the importance of VC funds' finite lifespan. Second, the most critical advantage of $\mathrm{VC}$ is its ability to serve as long-term committed patient capital to help start-ups achieve powerful sustained compounding of growth (Klingler-Vidra 2016; Arundale 2020). Hence, venture capitalists may selectively ignore time-flow inconsistency from overconfident beliefs in the ability to commit (Grenadier and Wang 2007).

This optimization problem, which solves the exit threshold of self 0 , is transformed into a two-stage optimization problem solved by backward induction. Self $L$ faces the case as the time-consistent venture capitalist. Then we analyze the exit timing selection of self 0 . Let $G(x)$ and $x_{G}$ denote the value function and exercise threshold for self 0 , respectively. Drawing on the continuation value function proposed by Grenadier and Wang (2007), $G(x)$ solves the differential equation:

$$
\frac{1}{2} \sigma^{2} x^{2} G^{\prime \prime}(x)+\alpha x G^{\prime}(x)-\rho G(x)+\lambda_{L}\left[F^{c}(x)-G(x)\right]=0,
$$

where $F^{c}(x)$ is self 0 's continuation value function, upon the arrival of self $L$, occurring at the intensity $\lambda_{L}$, and $F^{c}(x)=\delta_{p} F(x)$. Equation (15) is solved using the following valuematching and smooth-pasting conditions:

$$
G\left(x_{G}\right)=P_{V C}^{*}\left(x_{G}\right)-C=\eta x_{G}-\theta, \quad G^{\prime}\left(x_{G}\right)=\left[P_{V C}^{*}\left(x_{G}\right)-C\right]^{\prime}=\eta .
$$

After standard calculations, we obtain the exit exercise threshold and option value for the time-point-inconsistent venture capitalist.

Proposition 1 For the time-point-inconsistent venture capitalist, the value of the exit option is as follows:

$$
G(x)=\frac{\eta\left(\beta_{1}-1\right)}{\beta_{2}-\beta_{1}}\left(x^{*}-x_{G}\right)\left(\frac{x}{x_{G}}\right)^{\beta_{2}}+\delta_{p} F(x),
$$

where $\beta_{2}=\frac{1}{2}-\frac{\alpha}{\sigma^{2}}+\sqrt{\left(\frac{\alpha}{\sigma^{2}}-\frac{1}{2}\right)^{2}+\frac{2\left(\rho+\lambda_{L}\right)}{\sigma^{2}}}>\beta_{1}$ and $x_{G}$ is the optimal exit threshold given by

$$
x_{G}=\frac{1}{\eta\left(\beta_{2}-1\right)}\left[\beta_{2} \theta+\left(\beta_{2}-\beta_{1}\right) \delta_{p} F\left(x_{G}\right)\right] .
$$

\section{Naïve venture capitalists}

The naïve venture capitalist realizes time-point inconsistency but misunderstands the decision criterion of future selves generated by time-flow inconsistency. In our model, this type of venture capitalist believes that self $n(n=1 \sim L-1)$ will adopt strategies consistent with the current self (self 0 ). In other words, the discount function $D_{n}(t, s)$ ( $n=1 \sim L-1$ ) will not update and is always equal to $D_{0}(t, s)$. Thus, it is a three-stage optimization problem solved by backward induction. 
First, let us consider the optimization problem from the perspective of self $L$. As mentioned above, self $L$ faces the case as the time-consistent VC. Let $N_{L}(x)$ and $x_{N, L}$ denote self $L$ 's value function and exercise threshold, respectively.

$$
\begin{aligned}
& N_{L}(x)=F(x)=\left(\frac{x}{x^{*}}\right)^{\beta_{1}}\left(\eta x^{*}-\theta\right) . \\
& x_{N, L}=x^{*}=\frac{\beta_{1} \theta}{\left(\beta_{1}-1\right) \eta} .
\end{aligned}
$$

Then, self 1 faces the case in which there is only self $L$ in the future. This situation is similar to that of the time-point-inconsistent venture capitalist. The only difference is in the arrival intensity of self $L$. Self 1's value function $N_{1}(x)$ and exercise threshold $x_{N, 1}$ are given in Eqs. (20) and (21).

$$
\begin{aligned}
& N_{1}(x)=\frac{\eta\left(\beta_{1}-1\right)}{\beta_{3}-\beta_{1}}\left(x^{*}-x_{N, 1}\right)\left(\frac{x}{x_{N, 1}}\right)^{\beta_{3}}+\delta_{p} F(x), \\
& x_{N, 1}=\frac{1}{\eta\left(\beta_{3}-1\right)}\left[\beta_{3} \theta+\left(\beta_{3}-\beta_{1}\right) \delta_{p} F\left(x_{N, 1}\right)\right],
\end{aligned}
$$

where $\beta_{3}=\frac{1}{2}-\frac{\alpha}{\sigma^{2}}+\sqrt{\left(\frac{\alpha}{\sigma^{2}}-\frac{1}{2}\right)^{2}+\frac{2\left(\rho+\lambda_{p N}\right)}{\sigma^{2}}}>\beta_{2}>\beta_{1}$.

Next, self 0 decides their exercise threshold $x_{N, 0}$, considering their future selves' exercise thresholds. The continuation value function $N_{1}^{c}(x)$ of self 0 is calculated as follows. If self 1 is alive when their threshold $x_{N, 1}$ is reached, then the exit option is exercised, and its payoff to self 0 is $\delta_{f}\left[P_{V C}^{*}\left(x_{N, 1}\right)-C\right]$. However, if self 1 dies and self $L$ arrives before $x_{N, 1}$ is reached, then self 0 's continuation value $N_{1}^{c}(x)$ changes into self 1's continuation value $F^{c}(x)$. Thus, $N_{1}^{c}(x)$ solves the following differential equation:

$$
\frac{1}{2} \sigma^{2} x^{2} N_{1}^{c \prime \prime}(x)+\alpha x N_{1}^{c \prime}(x)-\rho N_{1}^{c}(x)+\lambda_{p N}\left[F^{c}(x)-N_{1}^{c}(x)\right]=0,
$$

where $F^{c}(x)=\delta_{p} F(x)$, the value-matching condition is given by

$$
N_{1}^{c}\left(x_{N, 1}\right)=\delta_{f}\left[P_{V C}^{*}\left(x_{N, 1}\right)-C\right]=\delta_{f}\left(\eta x_{N, 1}-\theta\right) .
$$

The value-matching condition ensures the continuity of the continuation value function. We note that solving $N_{1}^{c}(x)$ only requires a boundary condition. To simplify the expression, we assume that $Y=x_{N, 1}^{-\beta_{3}}\left[\delta_{f}\left(\eta x_{N, 1}-\theta\right)-\delta_{p} F\left(x_{N, 1}\right)\right]$. Self 0's continuation value function is $N_{1}^{c}(x)=Y x^{\beta_{3}}+\delta_{p} F(x)$.

Self 0 maximizes their value function $N_{0}(x)$ by taking the continuation value function $N_{1}^{c}(x)$ and choosing their exit threshold $x_{N, 0}$. Thus, $N_{1}^{c}(x)$ solves the differential equation:

$$
\frac{1}{2} \sigma^{2} x^{2} N_{0}^{\prime \prime}(x)+\alpha x N_{0}^{\prime}(x)-\rho N_{0}(x)+\lambda_{f}\left[N_{1}^{c}(x)-N_{0}(x)\right]=0 .
$$

It is solved by using the value-matching and smooth-pasting conditions: 


$$
N_{0}\left(x_{N, 0}\right)=P_{V C}^{*}\left(x_{N, 0}\right)-C=\eta x_{N, 0}-\theta, \quad N_{0}^{\prime}\left(x_{N, 0}\right)=\left[P_{V C}^{*}\left(x_{N, 0}\right)-C\right]^{\prime}=\eta
$$

We assume that the general solution of $N_{0}(x)$ takes the form below, and we verify the conjecture in "Appendix 1". Next, we discuss case by case.

$$
N_{0}(x)=\left\{\begin{array}{l}
\delta_{p} F(x)+\varepsilon Y x^{\beta_{3}}+U_{0} x^{\beta_{4}}, \quad \text { if } \lambda_{f} \neq \lambda_{p N}, \\
\delta_{p} F(x)+R_{1} x^{\beta_{4}} \log x+R_{0} x^{\beta_{4}}, \quad \text { if } \lambda_{f}=\lambda_{p N} .
\end{array}\right.
$$

Proposition 2 If $\lambda_{f} \neq \lambda_{p N}$, we note that $\beta_{3} \neq \beta_{4}$. The value of the naïve venture capitalist exit option is given by.

$$
N_{0}(x)=\delta_{p} F(x)+\varepsilon Y x^{\beta_{3}}+U_{0} x^{\beta_{4}},
$$

where $\quad \varepsilon=\frac{\lambda_{f}}{\lambda_{f}-\lambda_{p N}}, \quad U_{0}=x_{N, 0}^{-\beta_{4}}\left[\eta x_{N, 0}-\theta-\delta_{p} F\left(x_{N, 0}\right)-\varepsilon Y x_{N, 0}^{\beta_{3}}\right]$, $\beta_{4}=\frac{1}{2}-\frac{\alpha}{\sigma^{2}}+\sqrt{\left(\frac{\alpha}{\sigma^{2}}-\frac{1}{2}\right)^{2}+\frac{2\left(\rho+\lambda_{f}\right)}{\sigma^{2}}}$, and the exit threshold $x_{N, 0}$ is the solution to Eq. (26).

$$
x_{N, 0}=\frac{\beta_{4} \theta}{\eta\left(\beta_{4}-1\right)}+\frac{\beta_{4}-\beta_{1}}{\eta\left(\beta_{4}-1\right)} \delta_{p} F\left(x_{N, 0}\right)+\frac{\beta_{4}-\beta_{3}}{\eta\left(\beta_{4}-1\right)} \varepsilon Y x_{N, 0}^{\beta_{3}} .
$$

If $\lambda_{f}=\lambda_{p N}$, we note that $\beta_{3}=\beta_{4}$ (hereinafter referred to as $\beta_{4}$ ). The value of the naïve venture capitalist exit option is given by

$$
N_{0}(x)=\delta_{p} F(x)+R_{1} x^{\beta_{4}} \log x+R_{0} x^{\beta_{4}},
$$

where $R_{1}=-\frac{\lambda_{f} Y}{\alpha+\frac{1}{2} \sigma^{2}\left(2 \beta_{4}-1\right)}, \quad R_{0}=x_{N, 0}^{-\beta_{4}}\left[\eta x_{N, 0}-\theta-\delta_{p} F\left(x_{N, 0}\right)-R_{1} x_{N, 0}^{\beta_{4}} \log x_{N, 0}\right]$, and the exit threshold $x_{N, 0}$ is the solution to Eq. (28).

$$
x_{N, 0}=\frac{\beta_{4} \theta}{\eta\left(\beta_{4}-1\right)}+\frac{\beta_{4}-\beta_{1}}{\eta\left(\beta_{4}-1\right)} \delta_{p} F\left(x_{N, 0}\right)-\frac{R_{1} x_{N, 0}^{\beta_{4}}}{\eta\left(\beta_{4}-1\right)} .
$$

\section{Sophisticated venture capitalists}

The sophisticated venture capitalist foresees time-point and time-flow inconsistencies, as shown in Fig. 3. This type of venture capitalist clearly and correctly understands that all future selves will adopt strategies based on their own interests. Therefore, we need to start with self $L$, the last self, and backward derive value function, continuation value function, and exit threshold for each self until self 0 .

Similar to the naïve venture capitalist, we give self $L$ 's value function $S_{L}(x)$ and exercise threshold $x_{S, L}$ directly.

$$
\begin{aligned}
& S_{L}(x)=F(x)=\left(\frac{x}{x^{*}}\right)^{\beta_{1}}\left(\eta x^{*}-\theta\right) . \\
& x_{S, L}=x^{*}=\frac{\beta_{1} \theta}{\left(\beta_{1}-1\right) \eta} .
\end{aligned}
$$


Self $L-1$ faces the case similar to self 1 of the naïve venture capitalist. Let $S_{L-1}(x)$ and $x_{S, L-1}$ denote self $L-1$ 's value function and exercise threshold, respectively. It is noted that the arrival intensity of self $L$ changes again.

$$
\begin{aligned}
& S_{L-1}(x)=\frac{\eta\left(\beta_{1}-1\right)}{\beta_{5}-\beta_{1}}\left(x^{*}-x_{S, L-1}\right)\left(\frac{x}{x_{S, L-1}}\right)^{\beta_{5}}+\delta_{p} F(x), \\
& x_{S, L-1}=\frac{1}{\eta\left(\beta_{5}-1\right)}\left[\beta_{5} \theta+\left(\beta_{5}-\beta_{1}\right) \delta_{p} F\left(x_{S, L-1}\right)\right],
\end{aligned}
$$

where $\beta_{5}=\frac{1}{2}-\frac{\alpha}{\sigma^{2}}+\sqrt{\left(\frac{\alpha}{\sigma^{2}}-\frac{1}{2}\right)^{2}+\frac{2\left(\rho+\lambda_{p S}\right)}{\sigma^{2}}}$. In general, $\beta_{4} \geq \beta_{5}$.

We assume the general solution of $S_{L-2}(x)$ that satisfies the corresponding differential equation takes the form below, and we solve the exit threshold $x_{S, L-2}$ by the value-matching and smooth-pasting conditions.

$$
S_{L-2}(x)=\left\{\begin{array}{l}
\delta_{p} F(x)+\varphi Z^{\beta_{5}}+U_{L-2,0} x^{\beta_{4}}, \quad \text { if } \lambda_{f} \neq \lambda_{p S}, \\
\delta_{p} F(x)+R_{L-2,1} x^{\beta_{4}} \log x+R_{L-2,0} x^{\beta_{4}}, \quad \text { if } \lambda_{f}=\lambda_{p S} .
\end{array}\right.
$$

The proof for the general solution of $S_{L-2}(x)$ is similar to the case of the naive venture capitalist, so it is not repeated here.

(1) If $\lambda_{f} \neq \lambda_{p S}$, we note that $\beta_{4} \neq \beta_{5}$. Self $L-2$ 's exercise threshold $x_{S, L-2}$ is the solution to Eq. (34).

$$
x_{S, L-2}=\frac{\beta_{4} \theta}{\eta\left(\beta_{4}-1\right)}+\frac{\beta_{4}-\beta_{1}}{\eta\left(\beta_{4}-1\right)} \delta_{p} F\left(x_{S, L-2}\right)+\frac{\beta_{4}-\beta_{5}}{\eta\left(\beta_{4}-1\right)} \varphi Z x_{S, L-2}^{\beta_{5}},
$$

where $\varphi=\frac{\lambda_{f}}{\lambda_{f}-\lambda_{p S}}$ and $Z=x_{S, L-2}^{-\beta_{5}}\left[\delta_{f}\left(\eta x_{S, L-1}-\theta\right)-\delta_{p} F\left(x_{S, L-1}\right)\right]$.

In summary, for $n \leq L-3$, self $n$ 's continuation value function $S_{n+1}^{c}(x)$ satisfies the differential equation below:

$$
\frac{1}{2} \sigma^{2} x^{2} S_{n+1}^{c \prime \prime}(x)+\alpha x S_{n+1}^{c \prime}(x)-\rho S_{n+1}^{c}(x)+\lambda_{f}\left[S_{n+2}^{c}(x)-S_{n+1}^{c}(x)\right]=0 .
$$

The value-matching condition is given by

$$
S_{n+1}^{c}\left(x_{S, n+1}\right)=\delta_{f}\left[P_{V C}^{*}\left(x_{S, n+1}\right)-C\right]=\delta_{f}\left(\eta x_{S, n+1}-\theta\right) .
$$

The solutions for the continuation value functions $S_{n+1}^{c}(x)$ are presented in "Appendix 2", and $S_{n+1}^{c}(x)$ is given by

$$
S_{n+1}^{c}(x)=\delta_{p} F(x)+\varphi^{L-n-2} Z x^{\beta_{5}}+\sum_{i=0}^{L-n-3} W_{n+1, i}(\log x)^{i} x^{\beta_{4}},
$$

where the formula for $W_{n+1, i}$ is detailed in "Appendix 2".

Self $n+1$ 's value function $S_{n+1}(x)$ satisfies the following differential equation:

$$
\frac{1}{2} \sigma^{2} x^{2} S_{n+1}^{\prime \prime}(x)+\alpha x S_{n+1}^{\prime}(x)-\rho S_{n+1}(x)+\lambda_{f}\left[S_{n+2}^{c}(x)-S_{n+1}(x)\right]=0 .
$$


It is solved by using the value-matching and smooth-pasting conditions:

$$
S_{n+1}\left(x_{S, n+1}\right)=P_{V C}^{*}\left(x_{S, n+1}\right)-C=\eta x_{S, n+1}-\theta, \quad S_{n+1}^{\prime}\left(x_{S, n+1}\right)=\left[P_{V C}^{*}\left(x_{S, n+1}\right)-C\right]^{\prime}=\eta \text {. }
$$

The solutions for the value functions $S_{n+1}(x)$ are presented in "Appendix 3", and $S_{n+1}(x)$ is given by

$$
S_{n+1}(x)=\delta_{p} F(x)+\varphi^{L-n-2} Z x^{\beta_{5}}+\sum_{i=0}^{L-n-3} U_{n+1, i}(\log x)^{i} x^{\beta_{4}} .
$$

where the formula for $U_{n+1, i}$ is detailed in "Appendix 3".

(2) If $\lambda_{f}=\lambda_{p S}$, we note that $\beta_{4}=\beta_{5}$ (hereinafter referred to as $\beta_{4}$ ). Self $L-2$ 's exercise threshold $x_{S, L-2}$ is the solution to Eq. (39).

$$
x_{S, L-2}=\frac{\beta_{4} \theta}{\eta\left(\beta_{4}-1\right)}+\frac{\beta_{4}-\beta_{1}}{\eta\left(\beta_{4}-1\right)} \delta_{p} F\left(x_{S, L-2}\right)-\frac{R_{L-2,1}}{\eta\left(\beta_{4}-1\right)} x_{S, L-2}^{\beta_{4}} \text {, }
$$

where $R_{L-2,1}=-\frac{\lambda_{f} Z}{\alpha+\frac{1}{2} \sigma^{2}\left(2 \beta_{4}-1\right)}$.

In summary, for $n \leq L-3$, self $n$ 's continuation value function $S_{n+1}^{c}(x)$ is given by

$$
S_{n+1}^{c}(x)=\delta_{p} F(x)+\sum_{i=0}^{L-n-2} V_{n+1, i}(\log x)^{i} x^{\beta_{4}} .
$$

Self $n+1$ 's value function $S_{n+1}(x)$ is given by

$$
S_{n+1}(x)=\delta_{p} F(x)+\sum_{i=0}^{L-n-2} R_{n+1, i}(\log x)^{i} x^{\beta_{4}} .
$$

The solutions for the continuation value function $S_{n+1}^{c}(x)$ and value function $S_{n+1}(x)$ are similar to those in $\lambda_{f} \neq \lambda_{p S}$, so it is not repeated here.

Proposition 3 If $\lambda_{f} \neq \lambda_{p S}$, we note that $\beta_{4} \neq \beta_{5}$. The value of the sophisticated venture capitalist exit option is given by

$$
S_{0}(x)=\delta_{p} F(x)+\varphi^{L-n-2} Z x^{\beta_{5}}+\sum_{i=0}^{L-2} U_{0, i}(\log x)^{i} x^{\beta_{4}}
$$

and the exit threshold $x_{S, 0}$ is as follows:

$$
\begin{aligned}
x_{S, 0}= & \frac{\beta_{3} \theta}{\eta\left(\beta_{3}-1\right)}+\frac{\beta_{3}-\beta_{1}}{\eta\left(\beta_{3}-1\right)} \delta_{p} F\left(x_{S, 0}\right)+\frac{\beta_{3}-\beta_{4}}{\eta\left(\beta_{3}-1\right)} \varphi^{L-1} Z x_{S, 0}^{\beta_{5}} \\
& -\frac{k}{\eta\left(\beta_{3}-1\right)} \sum_{k=1}^{L-2} U_{0, k}\left(\log x_{S, 0}\right)^{k-1} x_{S, 0}^{\beta_{4} .}
\end{aligned}
$$

If $\lambda_{f}=\lambda_{p S}$, we note that $\beta_{4}=\beta_{5}$ (hereinafter referred to as $\left.\beta_{4}\right)$. The value of the sophisticated venture capitalist exit option is given by 

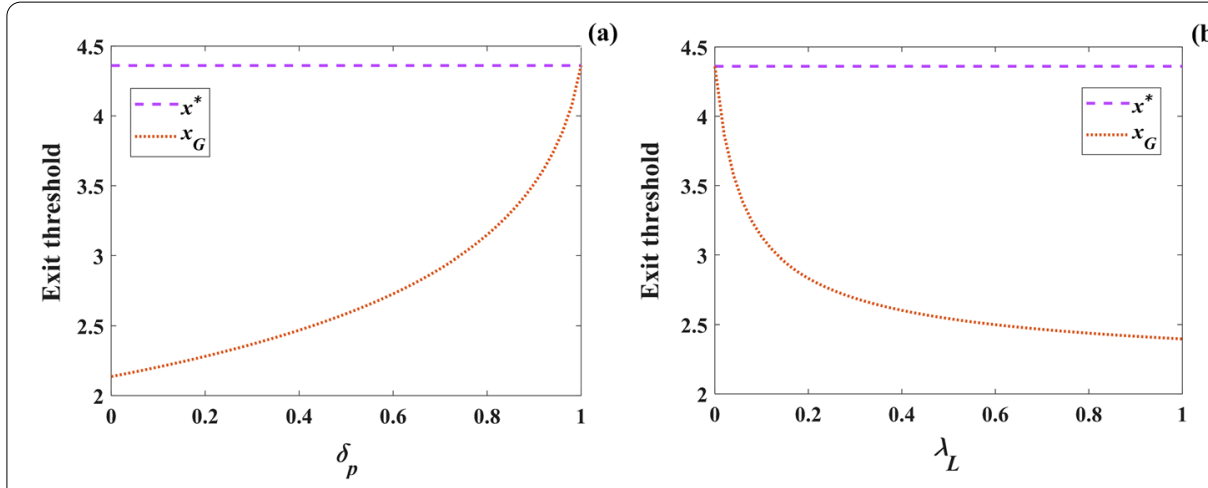

(b)

Fig. 4 Exit thresholds change with respect to the reduction factor $\delta_{p}$ and arrival intensity $\lambda_{L}$

$$
S_{0}(x)=\delta_{p} F(x)+\sum_{i=0}^{L-1} R_{0, i}(\log x)^{i} x^{\beta_{4}}
$$

where the derivation of $R_{0, i}$ is similar to that of $W_{0, i}$ (see "Appendix 2 " for details), and the exit threshold $x_{S, 0}$ is as follows:

$$
x_{S, 0}=\frac{\beta_{4} \theta}{\eta\left(\beta_{4}-1\right)}+\frac{\beta_{4}-\beta_{1}}{\eta\left(\beta_{4}-1\right)} \delta_{p} F\left(x_{S, 0}\right)-\frac{k}{\eta\left(\beta_{4}-1\right)} \sum_{k=1}^{L-1} R_{0, k}\left(\log x_{S, 0}\right)^{k-1} x_{S, 0}^{\beta_{4}} .
$$

\section{Model implications}

This section compares the exit thresholds of the four types of venture capitalists by numerically examining the properties of the model solutions. The base parameter values are set as $\alpha=0.02, \sigma=0.2$, and $\rho=0.06$ according to Dixit and Pindyck (1994), and ensuring $\rho>\alpha$ for convergence; $Q^{M}=1.7, Q^{A}=1$, and $Q^{T}=0.5$ based on Thijssen (2008) and ensuring $Q^{M}>Q^{A}+Q^{T}$ for the positive synergy; the VC's negotiation ability $\beta_{V C}=0.2$ (can be anywhere from 0 to 1); the VC's holding shares $\phi=0.4$ (can be anywhere from 0 to 1 ); the VC's preferential fixed claim $d=0.4$; and the exit cost $C=10$.

\section{Comparison of time-consistent and time-point-inconsistent venture capitalists}

Figure 4 shows how the exit thresholds $x^{*}$ of time-consistent venture capitalists and $x_{G}$ of time-point-inconsistent venture capitalists change with parameters $\delta_{p}$ and $\lambda_{L}$, respectively. We separately set $\lambda_{L}=1$ in Fig. $4 \mathrm{a}$ and $\delta_{p}=0.3$ in Fig. $4 \mathrm{~b}$. Our results show that time-point-inconsistent venture capitalists exit earlier than time-consistent venture capitalists, in that $x_{G}<x^{*}$. We also observe that as the reduction factor $\delta_{p}$ increases from 0 to 1 or the arrival intensity $\lambda_{L}$ decreases from 1 to 0 , the degree of time inconsistency gradually decreases, and the exit threshold $x_{G}$ gradually approaches $x^{*}$.

The economic intuition for these findings is as follows. The exit decision of the timepoint-inconsistent venture capitalist is determined by the current and the future selves. The VC fund's expiration can be viewed as the death of the current self and the birth of the future self, meaning that the future self starts to take over the right to make exit decisions. Considering that the payoffs obtained from exercising the exit option by the future 


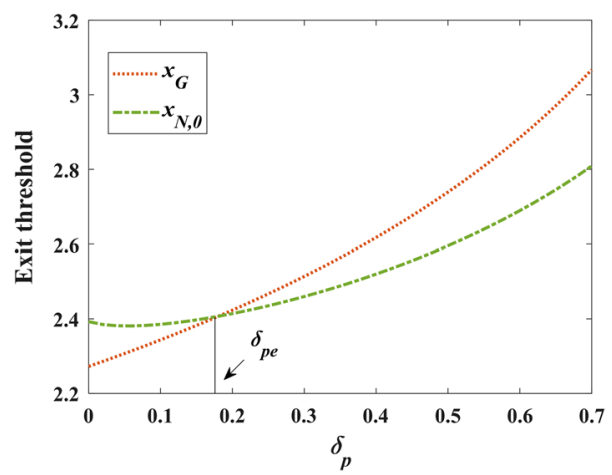

Fig. 5 Exit thresholds change with the reduction factor $\delta_{p}$ under $\lambda_{f}=\lambda_{p N}=1$

self should be further discounted by an extra reduction factor, the current self prefers to exercise the option by oneself. As a result, time-inconsistent preferences accelerate the exit of venture capitalists. Venture capitalists managing young and less-prestigious VC funds are more sensitive to fund expiration and more prone to time-inconsistent preferences than those in charge of older VC funds. Therefore, we conclude that young VCs exit earlier than older VCs. This conclusion is also supported by recent empirical evidences (Amor and Kooli 2020; Sethuram et al. 2021).

\section{Comparison of the three defined time-inconsistent venture capitalists}

Figures 5 and 6 demonstrate how the exit thresholds $x_{G}$ of time-point-inconsistent venture capitalists and $x_{N, 0}$ of naive venture capitalists change with the parameter $\delta_{p}$ under $\lambda_{f}=\lambda_{p N}$ and $\lambda_{f} \neq \lambda_{p N}$, respectively. To ensure $\delta_{f} \geq \delta_{p}$, we set $\delta_{f}=0.7$ and $\delta_{p}$ from 0 to 0.7 . To model the different durations left before the expiry date, we examine the exit thresholds of the above two types of venture capitalists by adjusting $\lambda_{p N}$ while keeping $\lambda_{f}=1$ all the time. The time-point-inconsistent venture capitalist is directly faced with the pressure of the $\mathrm{VC}$ fund's expiration, while the naïve venture capitalist is also faced with the pressure of time-flow inconsistency in addition to the $\mathrm{VC}$ fund's expiration.

Let us begin with a special case of $\lambda_{f}=\lambda_{p N}$. Figure 5 shows that $x_{G}>x_{N, 0}$ at $\delta_{p}>0.18$, and $x_{G}<x_{N, 0}$ at $\delta_{p}<0.18$. Thus, we represent the intersection point where $\delta_{p}=0.18$ as $\delta_{p e}$. We find that when $\delta_{p}=\delta_{f}=0.7$ (i.e., we do not distinguish between two kinds of time inconsistencies), our model evolves as the case of Grenadier and Wang (2007), and the exit threshold of the time-point-inconsistent venture capitalist is strictly greater than that of the naïve venture capitalist. Nevertheless, we note that when $\delta_{p}<\delta_{p e}$, the naïve venture capitalist abnormally exits later than the time-point-inconsistent venture capitalists. In this case, the time-point-inconsistent venture capitalist faces the powerful but distant VC fund's expiration pressure. In contrast, the naïve venture capitalist also faces the above expiration pressure but faces a low degree of pressure from time-flow inconsistency in the first place. For the naïve venture capitalist, the future self caused by timeflow inconsistency may act as a buffer against the detrimental effect, thus weakening the impact of time-point inconsistency. We further test this inference by comparing the exit thresholds of naïve and sophisticated venture capitalists.

Now let us analyze the more general cases of $\lambda_{f} \neq \lambda_{p N}$. Figure $6 \mathrm{a}-\mathrm{d}$ are the cases where $\lambda_{p N}=0.8,0.5,0.2$ and 0.05 , respectively. We find that as $\lambda_{p N}$ decreases, both 


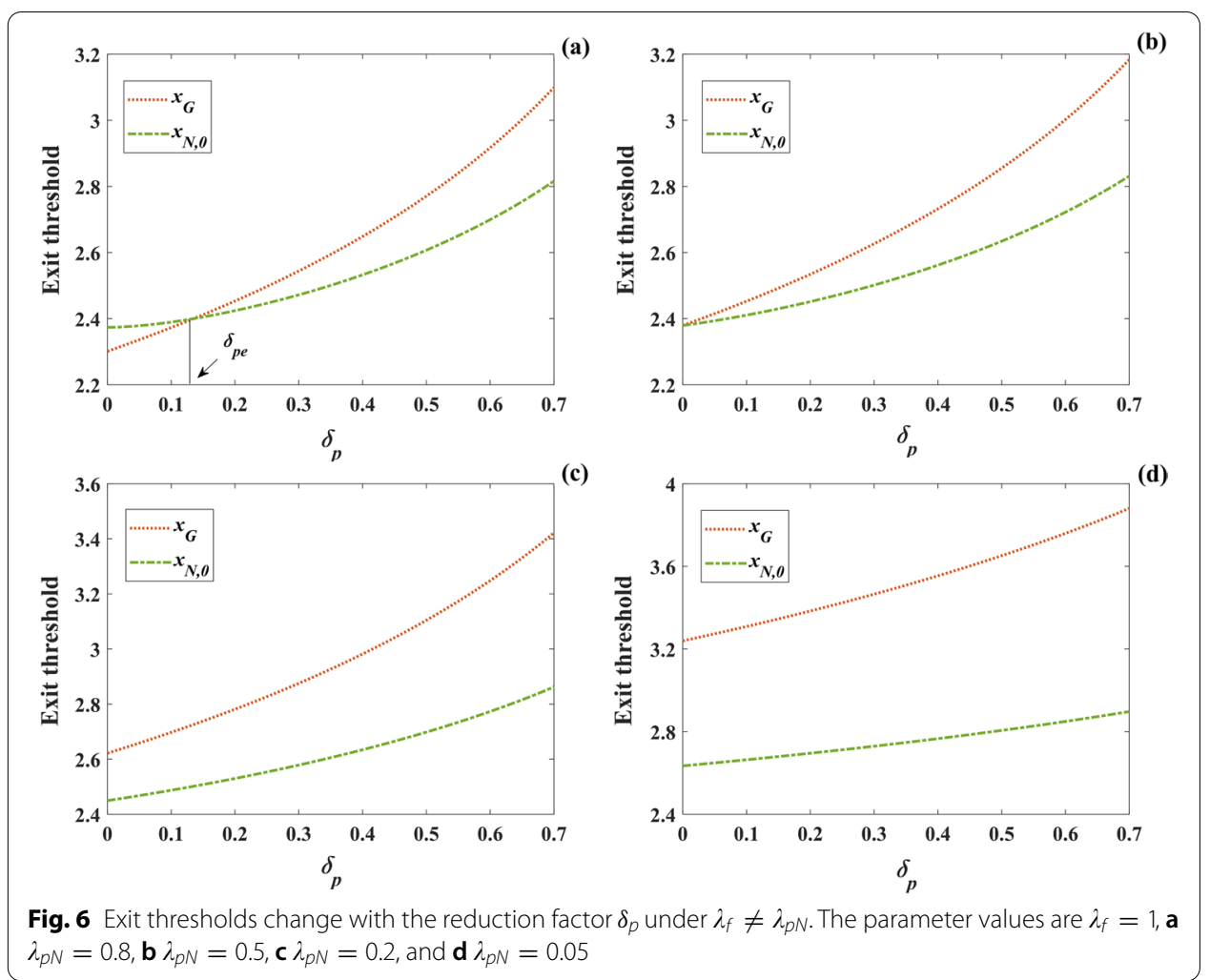

$x_{G}$ and $x_{N, 0}$ increase while the increase of $x_{G}$ is greater than that of $x_{N, 0}$. When $\lambda_{p N}$ decreases to a specific value, $x_{G}$ is completely greater than $x_{N, 0}$. These findings suggest that the farther the expiry dates are, the more the two types of venture capitalists delay their exit. However, considering that we adjust $\lambda_{p N}$ while keeping $\lambda_{f}$ unchanged, the exit threshold of the time-point-inconsistent venture capitalist is more affected than that of the naïve venture capitalist. The intuition is straightforward. As the duration left before the expiry date increases, the impact from the VC fund's expiration decreases, leading to the further prominent effect of time-flow inconsistency. In addition, it's worth noting that the case of $\lambda_{f} \gg \lambda_{p N}$, that is, the result shown in Fig. 6 is the most common in reality. After all, the future self, caused by individual time preferences, arrives earlier than the $\mathrm{VC}$ fund expiry date. Therefore, the naïve venture capitalist typically exits earlier than the time-point-inconsistent venture capitalist.

Figure 7 shows how the exit thresholds $x_{G}, x_{N, 0}$ and $x_{S, 0}$ change with the parameter $\delta_{p}$ under different numbers of selves generated by time-flow inconsistency. We set $\lambda_{f}=\lambda_{p S}=0.5$ for facilitating the calculation and $\delta_{f}=0.7$ as in the above cases. Hence, the number of selves $E+1$ reflects the different durations left before the expiry date. Due to the complicated derivation, we only provide three cases where $L+1=4,5$, and 6 , respectively.

We denote the intersection of curves $x_{G}$ and $x_{S, 0}$ as $\delta_{p G}$ and the intersection of curves $x_{N, 0}$ and $x_{S, 0}$ as $\delta_{p s}$, respectively. As shown in Fig. 7a, when $\delta_{p}>\delta_{p s}$, especially when $\delta_{p}=\delta_{f}=0.7$, our model evolves as the case of Grenadier and Wang (2007) again and we find that sophisticated venture capitalists exit earlier than naïve venture capitalists, 


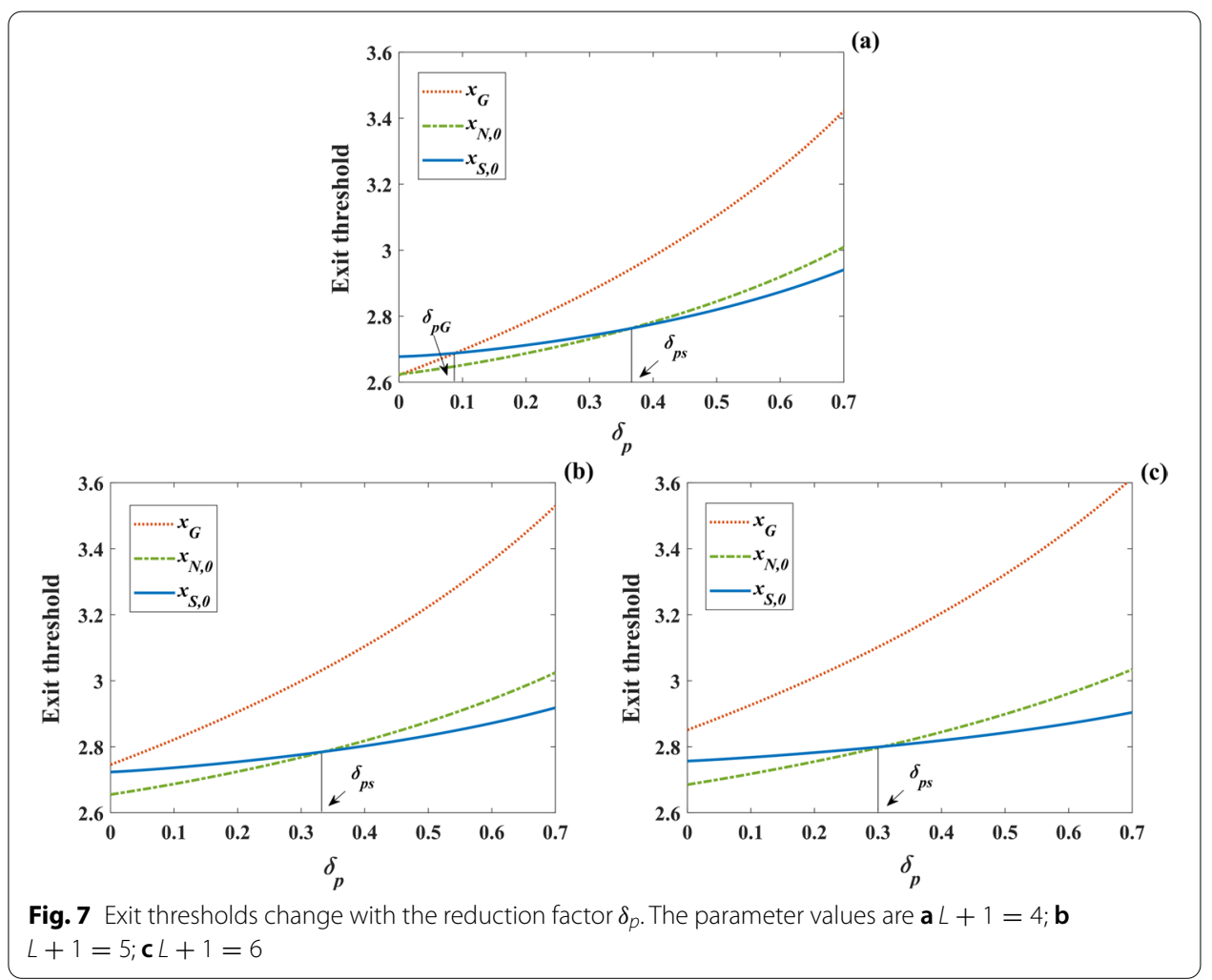

who in turn exit earlier than time-point-inconsistent venture capitalists. When $\delta_{p}<\delta_{p G}$ and $\delta_{p G}<\delta_{p}<\delta_{p s}$, we observe that $x_{S, 0}>x_{G}>x_{N, 0}$ and $x_{G}>x_{S, 0}>x_{N, 0}$, respectively. These results confirm the inference we propose in our analysis of Fig. 5 that the future selves caused by time-flow inconsistency weaken the effect of time-point inconsistency. Particularly, sophisticated venture capitalists exit later than naïve venture capitalists because they are fully aware of multiple future selves caused by time-flow inconsistency, further weakening the effect of time-point inconsistency.

Moreover, it is observed that the growth degree of $x_{G}, x_{N, 0}$ and $x_{S, 0}$ decreases in turn with the number of selves $L+1$ increasing. This result indicates that a gradual increase in the number of future selves enhances the dominant effect of time-flow inconsistencies on the sophisticated venture capitalist, thereby prompting the current self to make the exit decision earlier than the naïve venture capitalist. Thus, it is foreseeable that when the number of future selves reaches a specific threshold, the sophisticated venture capitalist exits earlier than the naïve venture capitalist, who in turn exits earlier than the time-point-inconsistent venture capitalist. This finding is also in line with the real-world practice because the arrival intensity of time-flow inconsistency is usually much greater than that of time-point inconsistency.

\section{Conclusions}

This study merges time-inconsistent preferences and $\mathrm{VC}$ exit decisions under uncertainty. In transition economies such as China, many VC funds have been set up and put into operation. For young and less-prestigious VC funds, obtaining significant payoffs and exiting successfully before the $\mathrm{VC}$ fund's expiration could effectively signal the high 
quality of the $\mathrm{VC}$ fund and guarantee follow-up fundraising. Consequently, venture capitalists are faced with two opposite decision drivers: waiting for the optimal exit and exiting early to gain reputational value. In this study, the time-inconsistent preferences of venture capitalists are incorporated into the optimal exit option framework to model the above VC exit decisions accurately.

Considering that both individual time preferences and the finite lifespan of $\mathrm{VC}$ funds contribute to the time-inconsistent preferences of venture capitalists, two kinds of time inconsistencies (i.e., time-flow and time-point inconsistencies) are proposed. Based on the assumption of time inconsistencies described, we derive and compare the exit thresholds of the four types of venture capitalists. The main findings of the numerical experiments are as follows. First, time-inconsistent preferences accelerate the exit of venture capitalists and thus all types of time-inconsistent venture capitalists exit earlier than time-consistent ones. Our model is the first to provide a behavioral explanation for the empirical facts of young VCs' grandstanding from the perspective of decision-makers' time preferences. Second, the closer the VC funds expiry dates are, the more likely time-inconsistent venture capitalists are to accelerate their exits. Third, future selves caused by time-flow inconsistency weaken the effect of time-point inconsistency. Our findings fully explain both the standard and abnormal phenomena. Generally, sophisticated venture capitalists exit earlier than naïve venture capitalists, who in turn exits earlier than time-point-inconsistent venture capitalists. As for some special situations when the degree of time-point inconsistency is much greater than that of time-flow inconsistency, and the exit opportunity is close to the VC fund's expiry date, naive venture capitalists exit later than time-point-inconsistent venture capitalists, and sophisticated venture capitalists exit last among the three defined time-inconsistent venture capitalists.

The two possible extensions to this study are introduced below. First, our study follows previous literature and assumes that the discount reduction factor $\delta_{f}$ is fixed for each self. Nevertheless, a more realistic assumption would be that the closer to the expiration date, the smaller $\delta_{f}$ is. Second, it is assumed that venture capitalists retain control over their capital exit from the invested firm. Although in reality venture capital contracts do have provisions to give venture capitalists this right, ${ }^{8}$ entrepreneurs lose the private benefits of control and hence may oppose trade sales. Therefore, the model could be extended to account for the game between the entrepreneur, the venture capitalist, and the acquiring firm.

\section{Appendix 1}

The proof for the general solution of $N_{0}(x)$.

The general solution we assume is given by

$$
N_{0}(x)=\left\{\begin{array}{l}
\delta_{p} F(x)+\varepsilon Y x^{\beta_{3}}+U_{0} x^{\beta_{4}}, \quad \text { if } \lambda_{f} \neq \lambda_{p N}, \\
\delta_{p} F(x)+R_{1} x^{\beta_{4}} \log x+R_{0} x^{\beta_{4}}, \quad \text { if } \lambda_{f}=\lambda_{p N} .
\end{array}\right.
$$

\footnotetext{
${ }^{8}$ For example, drag-along rights and tag-along rights, see Cumming (2010) and Bienz and Walz (2010).
} 
Take the first and second derivatives of $N_{0}(x)$ and substitute them into the following differential equation:

$$
\frac{1}{2} \sigma^{2} x^{2} N_{0}^{\prime \prime}(x)+\alpha x N_{0}^{\prime}(x)-\rho N_{0}(x)+\lambda_{f}\left[N_{1}^{c}(x)-N_{0}(x)\right]=0 .
$$

(1) If $\lambda_{f} \neq \lambda_{p N}$, we note that $\beta_{3} \neq \beta_{4}$.

For the $x^{\beta_{1}}$ term, we have

$$
\delta_{p} F(x)\left[\frac{1}{2} \sigma^{2} \beta_{1}\left(\beta_{1}-1\right)+\alpha \beta_{1}-\rho\right]=0 .
$$

For the $x^{\beta_{3}}$ term, we have

$$
\frac{1}{2} \sigma^{2} \beta_{3}\left(\beta_{3}-1\right) x^{\beta_{3}} \varepsilon Y+\alpha \beta_{3} x^{\beta_{3}} \varepsilon Y-\rho x^{\beta_{3}} \varepsilon Y+\lambda_{f}\left[x^{\beta_{3}} Y-x^{\beta_{3}} \varepsilon Y\right]=0 .
$$

Simplify the above Eq. (49), we obtain

$$
\varepsilon=\frac{\lambda_{f}}{\lambda_{f}-\lambda_{p N}} .
$$

For the $x^{\beta_{4}}$ term, we have

$$
U_{0} x^{\beta_{4}}\left[\frac{1}{2} \sigma^{2} \beta_{4}\left(\beta_{4}-1\right)+\alpha \beta_{4}-\left(\rho+\lambda_{f}\right)\right]=0 .
$$

(2) If $\lambda_{f}=\lambda_{p N}$, we note that $\beta_{3}=\beta_{4}$.

For the $x^{\beta_{1}}$ term, we have

$$
\delta_{P} F(x)\left[\frac{1}{2} \sigma^{2} \beta_{1}\left(\beta_{1}-1\right)+\alpha \beta_{1}-\rho\right]=0 .
$$

For the $x^{\beta_{4}} \log x$ term, we have

$$
\begin{gathered}
R_{1} x^{\beta_{4}} \log x\left[\frac{1}{2} \sigma^{2} \beta_{4}\left(\beta_{4}-1\right)+\alpha \beta_{4}-\rho-\lambda_{f}\right] \\
+x^{\beta_{4}}\left[\frac{1}{2} \sigma^{2} R_{1}\left(2 \beta_{4}-1\right)+\alpha R_{1}+\lambda_{f} Y\right]=0 .
\end{gathered}
$$

Thus

$$
\frac{1}{2} \sigma^{2} R_{1}\left(2 \beta_{4}-1\right)+\alpha R_{1}+\lambda_{f} Y=0 .
$$

We obtain

$$
R_{1}=-\frac{\lambda_{f} Y}{\alpha+\frac{1}{2} \sigma^{2}\left(2 \beta_{4}-1\right)} .
$$

For the $x^{\beta_{4}}$ term, we have 


$$
R_{0} x^{\beta_{4}}\left[\frac{1}{2} \sigma^{2} \beta_{4}\left(\beta_{4}-1\right)+\alpha \beta_{4}-\left(\rho+\lambda_{f}\right)\right]=0 .
$$

\section{Appendix 2}

Solving for the continuation value function $S_{n+1}^{c}(x)$.

Let $n=N-(j+1)$, for $j=2,3, \ldots, N-1$. Then $S_{n+1}^{c}(x)=S_{N-j}^{c}(x)$. We assume the general solution of $S_{N-j}^{c}(x)$ is given in Eq. (57).

$$
S_{N-j}^{c}(x)=\delta_{p}\left(\frac{x}{x^{*}}\right)^{\beta_{1}}\left(\eta x^{*}-\theta\right)+\varphi^{j-1} Z x^{\beta_{5}}+\sum_{i=0}^{j-2} W_{N-j, i}(\log x)^{i} x^{\beta_{4}} .
$$

Further, it can be concluded that

$$
S_{N-j+1}^{c}(x)=\delta_{p}\left(\frac{x}{x^{*}}\right)^{\beta_{1}}\left(\eta x^{*}-\theta\right)+\varphi^{j-2} Z x^{\beta_{5}}+\sum_{i=0}^{j-3} W_{N-(j-1), i}(\log x)^{i} x^{\beta_{4}} .
$$

We substitute the general solutions of $S_{N-j}^{c}(x)$ and $S_{N-j+1}^{c}(x)$, and the first and second derivatives of $S_{N-j}^{c}(x)$ into the following differential equation:

$$
\frac{1}{2} \sigma^{2} x^{2} S_{N-j}^{c \prime \prime}(x)+\alpha x S_{N-j}^{c \prime}(x)-\rho S_{N-j}^{c}(x)+\lambda_{f}\left[S_{N-j+1}^{c}(x)-S_{N-j}^{c}(x)\right]=0 .
$$

For the $x^{\beta_{1}}$ term, Eq. (59) always stands up.

For the $x^{\beta_{5}}$ term, we have

$$
\frac{1}{2} \sigma^{2} \beta_{5}\left(\beta_{5}-1\right) x^{\beta_{5}} \varphi^{j-1} Z+\alpha \beta_{5} x^{\beta_{5}} \varphi^{j-1} Z-\rho x^{\beta_{5}} \varphi^{j-1} Z+\lambda_{f}\left[x^{\beta_{5}} \varphi^{j-2} Z-x^{\beta_{5}} \varphi^{j-1} Z\right]=0 .
$$

Simplify the above Eq. (60), we obtain

$$
\varphi=\frac{\lambda_{f}}{\lambda_{f}-\lambda_{p S}} .
$$

For the $x^{\beta_{4}}$ term, we set the coefficients for each $x^{\beta_{4}}(\log x)^{k}$ term to 0 and then we obtain

$$
\begin{aligned}
& \frac{\sigma^{2}}{2}\left[\left(2 \beta_{4}-1\right)(k+1) W_{N-j, k+1}+(k+2)(k+1) W_{N-j, k+2}\right] \\
& \quad+\alpha(k+1) W_{N-j, k+1}+\lambda_{f} W_{N-j+1, k}=0, \quad \text { for } \quad k=1,2, \ldots, j-1 .
\end{aligned}
$$

We assume that $\mu=\frac{-\beta_{4}}{\sigma^{2} \beta_{4}^{2} / 2+\rho+\lambda_{f}}$. The coefficient $W_{N-j, k}$ is given by

$$
W_{N-j, k}=\frac{\lambda_{f}}{k}\left[\mu \sum_{n=0}^{j-k-2}\left(\frac{\sigma^{2} \mu}{2}\right)^{n+1} W_{N-j+1, k+n} \prod_{m=0}^{n}(k+m)+\mu W_{N-j+1, k-1}\right] \text {, }
$$

for $k=1,2, \ldots, j-2$. And $W_{N-j, 0}$ is solved using the value-matching condition: 


$$
\begin{aligned}
W_{N-j, 0}= & x_{S, N-j}^{-\beta_{4}}\left[\delta_{f}\left(\eta x_{S, N-j}-\theta\right)-\delta_{p}\left(\frac{x_{S, N-j}}{x^{*}}\right)^{\beta_{1}}\left(\eta x^{*}-\theta\right)-\varphi^{j-1} Z x_{S, N-j}^{\beta_{5}}\right] \\
& -\sum_{i=1}^{j-2} W_{N-j, i}\left(\log x_{S, N-j}\right)^{i} .
\end{aligned}
$$

\section{Appendix 3}

Solving for the value function $S_{n+1}(x)$

Let $n=N-(j+1)$, for $j=2,3, \ldots, N-1$. Then $S_{n+1}(x)=S_{N-j}(x)$. We assume the general solution of $S_{N-j}(x)$ is given in Eq. (65).

$$
S_{N-j}(x)=\delta_{p}\left(\frac{x}{x^{*}}\right)^{\beta_{1}}\left(\eta x^{*}-\theta\right)+\varphi^{j-1} Z x^{\beta_{5}}+\sum_{i=0}^{j-2} U_{N-j, i}(\log x)^{i} x^{\beta_{4}} .
$$

We substitute the general solutions of $S_{N-j}(x)$ and $S_{N-j+1}(x)$, and the first and second derivatives of $S_{N-j}(x)$ into the following differential equation:

$$
\frac{1}{2} \sigma^{2} x^{2} S_{N-j}^{\prime \prime}(x)+\alpha x S_{N-j}^{\prime}(x)-\rho S_{N-j}(x)+\lambda_{f}\left[S_{N-j+1}^{c}(x)-S_{N-j}(x)\right]=0 .
$$

For the $x^{\beta_{1}}$ and $x^{\beta_{3}}$ term, we reach the same conclusions as "Appendix 2".

For the $x^{\beta_{4}}$ term, we set the coefficients for each $x^{\beta_{4}}(\log x)^{k}$ term to 0 and then we obtain

$$
\begin{aligned}
& \frac{\sigma^{2}}{2}\left[\left(2 \beta_{4}-1\right)(k+1) U_{N-j, k+1}+(k+2)(k+1) U_{N-j, k+2}\right] \\
& \quad+\alpha(k+1) U_{N-j, k+1}+\lambda_{f} W_{N-j+1, k}=0, \quad \text { for } \quad k=1,2, \ldots, j-2 .
\end{aligned}
$$

The coefficient $U_{N-j, k}$ is given by

$$
U_{N-j, k}=W_{N-j, k},
$$

for $k=1,2, \ldots, j-1$. And $U_{N-j, 0}$ is solved using the value-matching condition:

$$
\begin{aligned}
U_{N-j, 0}= & x_{S, N-j}^{-\beta_{4}}\left[\eta x_{S, N-j}-\theta-\delta_{p}\left(\frac{x_{S, N-j}}{x^{*}}\right)^{\beta_{1}}\left(\eta x^{*}-\theta\right)-\varphi^{j-1} Z x_{S, N-j}^{\beta_{5}}\right] \\
& -\sum_{i=1}^{j-2} U_{N-j, i}\left(\log x_{S, N-j}\right)^{i} .
\end{aligned}
$$

\section{Acknowledgements}

The authors thank the editor and the reviewers for invaluable comments and suggestions, which have improved the quality of this paper immensely.

\section{Authors' contributions}

YZ.L and J.G conceived of the presented idea. YZ.L participated in the design of the study and drafted the manuscript. J.G supervised the findings. S.S participated in project administration. YW.L participated in the design of the study and writing the manuscript. All the authors provided critical feedback and helped shape the research, analysis, and manuscript. All the authors read and approved the manuscript.

\section{Authors' information}

Yanzhao Li received bachelor degree of Engineering and bachelor degree of Economics from Xi'an Jiaotong University, China, in 2017. He is currently pursuing the Ph.D. degree in management science and engineering at School of Management, Xi'an Jiaotong University, China. His research interests include venture capital, behavioral finance, and data analysis. He has published one paper in Tourism Economics. 
Ju-e Guo received her Ph.D. degree in School of Management, Xi'an Jiaotong University, China, in 2001. She is currently a professor at School of Management, Xi'an Jiaotong University, China and executive deputy director of Research Center of Chinese Management. She has published more than 30 papers in international journals, such as Energy Economics and International Journal of Production Economics. Her research interests include investment and financing decision, risk management, and energy policy.

Shaolong Sun received his Ph.D. degree in Management Science and Engineering at the Institute of Systems Science, Academy of Mathematics and Systems Sciences, Chinese Academy of Sciences, China, in 2019. He is currently an associate professor at School of Management, Xi'an Jiaotong University, China. He has published over 20 papers in leading journals including Tourism Management, Energy Economics, and IEEE Transactions on Cybernetics. His research interests include big data mining, machine learning, and economic and financial forecasting.

Yongwu Li received his Ph.D. degree in Probability and Mathematical Statistics from Lanzhou University, Lanzhou, China, in 2014. Currently, he is an associate professor in the College of Economics and Management, Beijing University of Technology. He has published more than 20 papers in international journals, such as IEEE Systems Journal, Insurance: Mathematics and Economics, Journal of Optimization Theory and Applications, and Operations Research Letters. His research interests include financial engineering, mathematic finance, and the applications of stochastic control and optimization methods in operations research.

\section{Funding}

This paper was supported by the Major Program of the National Social Science Foundation of China under Grant No. 17ZDA083, the National Natural Science Foundation of China under Grant No. 71932002, and the Natural Science Foundation of Beijing Municipality under Grant No. 9192001.

\section{Availability of data and materials}

Not applicable.

\section{Declarations}

Competing interests

The authors declare that they have no competing interests.

\section{Author details}

'School of Management, Xi'an Jiaotong University, No. 28, Xianning West Road, Beilin District, Xi'an 710049, China.

${ }^{2}$ College of Economics and Management, Beijing University of Technology, No. 100, Ping Le Yuan, Chaoyang District, Beijing 100124, China.

Received: 25 May 2021 Accepted: 14 November 2021

Published online: 01 January 2022

\section{References}

Alvarez LHR, Stenbacka R (2006) Takeover timing, implementation uncertainty, and embedded divestment options. Rev Financ 10:417-441. https://doi.org/10.1007/s10679-006-9002-y

Amor SB, Kooli M (2020) Do M\&A exits have the same effect on venture capital reputation than IPO exits? J Bank Financ 111:105704. https://doi.org/10.1016/j.jbankfin.2019.105704

Anderson HD, Chi J, Wang Q (2017) Political ties and VC exits: evidence from China. China Econ Rev 44:48-66. https://doi. org/10.1016/j.chieco.2017.03.007

Arcot S (2014) Participating convertible preferred stock in venture capital exits. J Bus Ventur 29:72-87. https://doi.org/10. 1016/j.jbusvent.2013.06.001

Arcot S, Fluck Z, Gaspar J-M et al (2015) Fund managers under pressure: rationale and determinants of secondary buyouts. J Financ Econ 115:102-135. https://doi.org/10.1016/j.jfineco.2014.08.002

Arundale K (2020) Syndication and cross-border collaboration by venture capital firms in Europe and the USA: a comparative study. Ventur Cap 22:355-376. https://doi.org/10.1080/13691066.2020.1847414

Bienz C, Walz U (2010) Venture capital exit rights. J Econ Manag Strategy 19:1071-1116. https://doi.org/10.1111/j.15309134.2010.00278.x

Bock C, Schmidt M (2015) Should I stay, or should I go? - How fund dynamics influence venture capital exit decisions. Rev Financ Econ 27:68-82. https://doi.org/10.1016/j.rfe.2015.09.002

Butler AW, Goktan MS (2013) On the role of inexperienced venture capitalists in taking companies public. J Corp Financ 22:299-319. https://doi.org/10.1016/j.jcorpfin.2013.06.004

Chen S, Wang X, Deng Y et al (2016) Optimal dividend-financing strategies in a dual risk model with time-inconsistent preferences. Insur Math Econ 67:27-37. https://doi.org/10.1016/j.insmatheco.2015.11.005

Cumming D (2008) Contracts and exits in venture capital finance. Rev Financ Stud 21:1947-1982. https://doi.org/10. 1093/rfs/hhn072

Cumming D (2010) Venture capital: investment strategies, structures, and policies. Wiley, Hoboken

Cumming D (2012) The Oxford handbook of venture capital. Oxford University Press, Oxford

Cumming D, Fleming G, Schwienbacher A (2006) Legality and venture capital exits. J Corp Financ 12:214-245. https://doi. org/10.1016/j.jcorpfin.2004.12.004

Dixit AK, Pindyck RS (1994) Investment under uncertainty. Princeton University Press, Princeton

Félix EGS, Pires CP, Gulamhussen MA (2014) The exit decision in the European venture capital market. Quant Financ 14:1115-1130. https://doi.org/10.1080/14697688.2012.714903 
Ferreira RM, Pereira PJ (2021) A dynamic model for venture capitalists' entry-exit investment decisions. Eur J Oper Res 290:779-789. https://doi.org/10.1016/j.ejor.2020.08.014

Gao X, Ritter JR, Zhu Z (2013) Where have all the IPOs gone? J Financ Quant Anal 48:1663-1692. https://doi.org/10.1017/ S0022109014000015

Gompers P, Lerner J (1999) An analysis of compensation in the U.S. venture capital partnership. J Financ Econ 51:3-44. https://doi.org/10.1016/S0304-405X(98)00042-7

Gompers PA (1996) Grandstanding in the venture capital industry. J Financ Econ 42:133-156. https://doi.org/10.1016/ 0304-405X(96)00874-4

Grenadier SR, Malenko A (2011) Real options signaling games with applications to corporate finance. Rev Financ Stud 24:3993-4036. https://doi.org/10.1093/rfs/hhr071

Grenadier SR, Wang N (2007) Investment under uncertainty and time-inconsistent preferences. J Financ Econ 84:2-39. https://doi.org/10.1016/j.jineco.2006.01.002

Guo D, Jiang K (2013) Venture capital investment and the performance of entrepreneurial firms: Evidence from China. J Corp Financ 22:375-395. https://doi.org/10.1016/j.jcorpfin.2013.07.001

Guo Q-W, Chen S, Schonfeld P et al (2018) How time-inconsistent preferences affect investment timing for rail transit. Transp Res Pt B-Methodol 118:172-192. https://doi.org/10.1016/j.trb.2018.10.009

Harris C, Laibson D (2013) Instantaneous gratification. Q J Econ 128:205-248. https://doi.org/10.1093/qje/qj5051

Kandel E, Leshchinskii D, Yuklea H (2011) VC funds: aging brings myopia. J Financ Quant Anal 46:431-457. https://doi.org/ $10.1017 / \mathrm{s} 0022109010000840$

Kaplan SN, Strömberg P (2003) Financial contracting theory meets the real world: an empirical analysis of venture capital contracts. Rev Econ Stud 70:281-315. https://doi.org/10.1111/1467-937X.00245

Klingler-Vidra R (2016) When venture capital is patient capital: seed funding as a source of patient capital for high-growth companies. Socio-Econ Rev 14:691-708. https://doi.org/10.1093/ser/mww022

KPMG (2019) Venture Pulse Q4 2018. Available at: https://assets.kpmg/content/dam/kpmg/xx/pdf/2019/01/kpmg-ventu re-pulse-q4-2018.pdf

Laibson D (1997) Golden eggs and hyperbolic discounting. Q J Econ 112:443-478. https://doi.org/10.1162/0033553975 55253

Lee PM, Wahal S (2004) Grandstanding, certification and the underpricing of venture capital backed IPOs. J Financ Econ 73:375-407. https://doi.org/10.1016/j.jfineco.2003.09.003

Li H, Mu C, Yang J (2016) Optimal contract theory with time-inconsistent preferences. Econ Model 52:519-530. https:// doi.org/10.1016/j.econmod.2015.09.032

Li X, Wu X, Zhou W (2017) Optimal stopping investment in a logarithmic utility-based portfolio selection problem. Financ Innov 3:28, https://doi.org/10.1186/s40854-017-0080-y

Liu L, Niu Y, Wang Y et al (2020) Optimal consumption with time-inconsistent preferences. Econ Theory 70:785-815. https://doi.org/10.1007/s00199-019-01228-1

Loewenstein G, Prelec D (1992) Anomalies in intertemporal choice: evidence and an interpretation. Q J Econ 107:573597. https://doi.org/10.2307/2118482

Luo P, Tian Y, Yang Z (2020) Real option duopolies with quasi-hyperbolic discounting. J Econ Dyn Control 111:103829. https://doi.org/10.1016/j.jedc.2019.103829

O’Donoghue T, Rabin M (1999) Doing it now or later. Am Econ Rev 89:103-124. https://doi.org/10.1257/aer.89.1.103

Sethuram S, Taussig M, Gaur A (2021) A multiple agency view of venture capital investment duration: the roles of institutions, foreignness, and alliances. Glob Strateg J. https://doi.org/10.1002/gsj.1402

Strotz RH (1955) Myopia and inconsistency in dynamic utility maximization. Rev Econ Stud 23:165-180. https://doi.org/ $10.2307 / 2295722$

Tavares-Gärtner M, Pereira PJ, Brandão E (2018) Heterogeneous beliefs and optimal ownership in entrepreneurial financing decisions. Quant Financ 18:1947-1958. https://doi.org/10.1080/14697688.2018.1432882

Thaler R (1981) Some empirical evidence on dynamic inconsistency. Econ Lett 8:201-207. https://doi.org/10.1016/01651765(81)90067-7

Thijssen JJJ (2008) Optimal and strategic timing of mergers and acquisitions motivated by synergies and risk diversification. J Econ Dyn Control 32:1701-1720. https://doi.org/10.1016/j.jedc.2007.06.016

Tian Y (2016) Optimal capital structure and investment decisions under time-inconsistent preferences. J Econ Dyn Control 65:83-104. https://doi.org/10.1016/j.jedc.2016.02.001

Wang Y, Huang W, Liu B et al (2020) Optimal effort in the principal-agent problem with time-inconsistent preferences. N Am Econ Financ 52:100909. https://doi.org/10.1016/j.najef.2019.01.006

Yoon H (2020) Impatience and time inconsistency in discounting models. Manag Sci 66:5850-5860. https://doi.org/10. $1287 /$ mnsc.2019.3496

\section{Publisher's Note}

Springer Nature remains neutral with regard to jurisdictional claims in published maps and institutional affiliations. 